\title{
Innovation and Practice of the Training Model for Postgraduates with Master's Degree in Clinical Medicine of Chongqing Medical University
}

\author{
Hu Weili \\ Graduate School, Chongqing Medical University, Chongqing, China
}

Email address:

184673716@qq.com

To cite this article:

$\mathrm{Hu}$ Weili. Innovation and Practice of the Training Model for Postgraduates with Master's Degree in Clinical Medicine of Chongqing Medical University. Mathematics and Computer Science. Vol. 4, No. 4, 2019, pp. 76-83. doi: 10.11648/j.mcs.20190404.11

Received: June 5, 2019; Accepted: July 12, 2019; Published: October 14, 2019

\begin{abstract}
To deepen the reform of clinical medical personnel training in an all-round way with the cooperation of medicine and education is the strategic adjustment direction of clinical postgraduate education in China. The goal of postgraduate education for master's degree in clinical medicine is to cultivate high-level medical and health professionals. Since 1998, the postgraduate education for master's degree in clinical medicine has been piloted in China. After 17 years of experiment and exploration, great progress has been made in clinical medical degree education. However, there are still difficulties in linking up with professional qualification certification, slow internationalization process and postgraduate students. There are many problems such as insufficient practical ability training. Chongqing Medical University combines its own long-term practice of postgraduate education in clinical medicine with its courage to explore and actively reform. Through improving the conditions of enrollment, innovating the training mode, adjusting the award marks and improving the system guarantee, it has effectively constructed the professional degree education of master of clinical medicine and standardized resident training. " $5+3$ " new training mode of training in combination. Since the implementation of the new training mode, the quality of postgraduate training has been significantly improved, the employment rate of graduates has been steadily improved, the influence of the school has been expanded, and the experience for relevant units to carry out the reform of postgraduate training mode of clinical medicine master's degree has also been provided for reference.
\end{abstract}

Keywords: Clinical Medicine, Master, Professional Degree, Training Model, Innovation

\section{Introduction}

Chongqing Medical University was founded in 1956. It was founded by the former Shanghai First Medical College (now Shanghai Medical College of Fudan University) and moved to Chongqing. Since 1979, it has enrolled doctoral and master's degree students. In 1981, it was approved as the first authorized unit of doctoral and master's degree in China. In 1998, it became the first batch of doctoral and master's degree in clinical medicine in China. Pilot units for professional degrees. Since 1998, the school has vigorously developed professional degree postgraduate education [1]. Since 2009, the school has been focusing on reforming the training mode of clinical master degree postgraduates (hereinafter referred to as clinical master). In view of the main problems existing in clinical master education, the school has carried out a series of reforms and explorations on the organic link between clinical master education and standardized resident training (hereinafter referred to as standard training). After more than five years of exploration and practice, the reforms have achieved remarkable results and have provided a training model for clinical master in China. The reform has opened up a new path and realized the organic link between professional degree education and vocational qualification certification. It not only guarantees the quality of professional degree postgraduate training, but also supplies a large number of high-quality talents for related industries. 


\section{Background of the Reform of Postgraduate Training Model for Master's Degree in Clinical Medicine}

For a long time, the medical postgraduates trained in our country are seriously lacking in practical operation ability, resulting in the embarrassing situation that "medical doctor will not see a doctor". To solve these problems, the Academic Degree Committee of the State Council officially launched the pilot work of clinical medicine professional degree in 1998. The development of postgraduate education of clinical medicine degree in China is faced with the characteristics of short time, complex training objects, multiple administrative departments involved in medical degree education, and diversified training channels [2]. How to reform the training mode of clinical master, improve the quality of training, and bring up a large number of high-level applied medical talents is the main problem for graduate educators.

In the long-term practice of training clinical master, Chongqing Medical University has gradually explored a new "5+3" training mode which combines clinical master education with regular training, and completed the educational practice of "Innovation and Practice of the Training Mode of Clinical Master Professional Degree in China"[3]. It has effectively solved the problems of imperfect training mode of clinical master, lack of mature training mode of high-level clinicians, low overall training quality of clinical master, inability of clinical master to apply for the qualification of practicing doctor, difficulty of effective connection with regular training, difficulty of seamless connection between professional degree education and industry admission standards, and inadaptability of current management system and mechanism to professional degree postgraduates. Educational development and other key problems of clinical master training.

\section{Main Contents of the Reform of the Training Model for Postgraduates with Master's Degree in Clinical Medicine in Chongqing Medical University}

The reform of training mode for clinical master of Chongqing Medical University is premised on defining training objectives, based on innovative training mode, with improving training quality as the core and linking up with professional qualification as the grasp [4]. The system reform of training mode for clinical master of Medical University has effectively solved the problem of insufficient practical ability of clinical master, and has realized the degree education and professional qualification recognition of clinical medicine specialty. The organic cohesion of syndromes has effectively improved the quality of clinical master training.

\subsection{Grasp the Strategic Adjustment Direction of Postgraduate Education in China and Define the Training Objectives}

At present, China's postgraduate education has entered a critical period of structural adjustment. To vigorously develop professional degree postgraduate education and improve the quality of training high-level applied talents is the focus of the current degree and postgraduate education work. The school accurately grasps the law of professional degree postgraduate education, changes the concept of professional degree postgraduate education, and orientates the training purpose of clinical master as "training doctors who can really see a doctor", aiming to improve the clinical practice ability of postgraduates as the main objective, and is in line with the training goal, thus laying a solid foundation for the organic connection between the two.

\subsection{Promoting the Organic Docking of Professional Degree Education and Vocational Qualification, Breaking the Bottleneck Problem}

The school has consulted with the industry authorities for many times and actively strived for it, which has been strongly supported by the industry authorities at higher levels. First, after one year's clinical training in the tertiary and first-class affiliated hospitals of the school, the clinical master who has not obtained the license of a licensed doctor is allowed to apply for the qualification examination of a licensed doctor, which solves the contradiction that the clinical master cannot obtain the license of a licensed doctor during the period of study [5]. The second is to allow the registration of licensed physicians from other places to the relevant departments of our university, which solves the problem of registering candidates who have obtained licenses for licensed physicians from different places in our school. Thirdly, we allow our clinical master not to take the entrance examination, but to be directly incorporated into the standardized resident training system, so that they can participate in the standardized resident training. The above policy support ensures that our clinical master can fully participate in clinical practice skills training and ensure the quality of training.

Under the above policy guarantee, the clinical master trained by the school has the dual status of postgraduate and regular trainee. After completing the relevant training content and passing the examination, the qualified certificate of licensed physician qualification and resident standardized training can be obtained. After completing the dissertation defense and meeting the award requirements, the graduate certificate and master's professional degree certificate can be obtained. "Four syndromes in one" has greatly saved the resources of education and training, and provided qualifications guarantee for the connection of clinical medical professional degree education and vocational qualification certification. 


\subsection{Strengthen the System Construction and Promote the Reform of the Training Mode of Master's Degree in Clinical Medicine}

\subsubsection{Innovation of Management System}

In order to effectively improve the quality of clinical master training and strengthen the management of clinical rotation process, the school has set up postgraduate management offices in clinical colleges, implemented the system of professional degree tutorial group, and established three-level management systems of schools (graduate schools), departments (graduate management offices) and clinical departments (tutorial groups) [6]. The Graduate Management Department of the Department organically integrates the training of clinical master's degree, the training of seven-year students' master's degree, and the application of resident doctors for master's degree related to the work of degree award, and arranges the clinical training and clinical competence assessment of clinical master's degree as a whole.

\subsubsection{Reforming the Tutorial System}

The tutorial responsibility system is applied in postgraduate training, but after clinical master's enters the clinical rotation, many times are not in the Department where the tutor is located, and there is a problem that no one manages the professional degree students when they rotate in the clinical departments outside the department [7]. The current single tutorial responsibility system can no longer meet the requirements of clinical rotation training, which is not conducive to the management and supervision of postgraduates.

To ensure the quality of clinical master's training, the school has set up a guidance group composed of the first tutor and rotating responsibility tutor. The tutor who applied for the postgraduate examination is the first tutor (defense tutor). Each clinical rotating Department of postgraduate clinical rotation appoints a teacher qualified as a professional master's tutor as rotating responsibility tutor to ensure that clinical master's is in clinical rotation. Effective management during the transition period.

\subsubsection{Establishing and Perfecting Rules and Regulations}

In order to consolidate the reform results of the training mode of clinical master, gradually standardize the management system and continuously improve the quality of training, the school continuously improves the rules and systems around the education of clinical master, covering the methods of re-examination admission, the quantitative assessment of the selection of tutors, the training program, the tutor group system, the curriculum, the professional course examination, the assessment of clinical ability, the regulation of publishing papers, the management of research funds and institutions [8]. In terms of setting up, a complete system of management rules for clinical master's degree has been established, and the experience of reform has been standardized and institutionalized, thus forming a long-term mechanism for linking professional degree education with professional qualification certification.

\subsubsection{Policy-oriented Guidance for the Rapid Development of Professional Degree Postgraduates}

The staff of the Graduate Management Department of the school conducted a thorough investigation on the effect, problems and suggestions of the training mode of clinical master's degree in various clinical departments, and held dozens of meetings to solve common problems. In order to speed up the development of professional degree postgraduate education, the school has formulated an enrollment policy conducive to the development of professional degree [9]. The deputy chief physician who meets the age requirement can recruit professional degree postgraduates, and more than two postgraduates must have one professional degree. At the same time, the workload of guiding professional degree postgraduates is directly linked to the promotion of their professional titles. Through the above measures, the problem of low enthusiasm of faculties and tutors in guiding graduate students with professional degrees has been solved, and the construction of professional degree tutors has been accelerated.

\subsubsection{Perfecting the System of Grants and Subsidies}

In view of the fact that the subsidy of clinical master is much lower than that of regular trainees during the clinical rotation period, the school has made many investigations and repeated demonstrations to improve the treatment of Postgraduates during the clinical rotation period and to improve the enthusiasm of students in clinical training [10]. Aiming at the characteristics of professional degree postgraduate education and adapting to the innovation of its training mode, the school has established a funding system different from academic degree postgraduates, and continuously improves the standards and coverage of grants. Excluding very few phenomena, the school grants cover $100 \%$ of the total, and the living allowance for clinical master's degree has also been greatly increased. Postgraduates with licensed doctor qualification and independent bed management are awarded 500 yuan in schools and hospitals, 500-1000 yuan in departments and tutors, and 2000-3000 yuan in living allowance per month for each clinical master.

\subsection{Innovation of Training Mode and Comprehensive Reform of Enrollment, Curriculum, Clinical Rotation and Degree Awarding}

\subsubsection{Improving Enrollment Conditions}

In order to provide a common basis for the follow-up process, it is necessary to ensure that the postgraduate enrollment conditions are equal to the basic conditions required by the professional qualification certification. Therefore, the school has improved the conditions for applying for clinical master's examination, so that it is consistent with the admission conditions of residents' standardized training: undergraduate majors should be clinical medicine, full-time national education series undergraduate graduates, to obtain bachelor's degree. After the admission of clinical master, the school will submit the list to Chongqing Municipal Health Bureau, and register it to Chongqing 
Municipal Health Bureau resident standardized training registration system without test.

\subsubsection{Reform of Curriculum System}

Our school has made corresponding reforms in the curriculum system of clinical master's degree. The reformed curriculum system not only meets the training objectives of clinical master, but also meets the requirements of theoretical knowledge for trainees. First of all, in order to ensure the clinical rotation time, the master of clinical courses in our school are arranged uniformly in the evening and weekend of the first semester. Secondly, the curriculum of Master of Clinical Science is adapted to the requirement of training students' theoretical knowledge and foreign language. It is closely related to clinical practice. The curriculum involves many independent modules, such as clinical research methods clinical diagnostics, internal medicine, surgery and so on [11]. Thirdly, according to the requirements of standardized resident training, and with the cooperation of training bases, starting from medical ethics, medical ethics, laws and regulations, professional ethics and basic clinical skills, we will offer lectures on medical law, applied psychology, humanistic literacy and doctor-patient communication to comprehensively improve the comprehensive quality of clinical master.

\subsubsection{Establishment of Standardized Clinical Rotation System}

The secondary schools awarded professional degrees in clinical medicine in our university are all the standardized training bases for residents in Chongqing. The secondary clinical colleges are responsible for both the health bureau, the training of residents and the school, and the training of postgraduates with professional degrees. Therefore, the training object, the training teachers and the responsible subjects can be combined into one, which provides a common basis for the integration of training. Students are brought into the "two levels, two stages" training after they enter school. According to whether the students have obtained the certificate of licensed physician, they are divided into two levels, and different awarding standards are formulated. The first stage of clinical rotation is one and a half years after enrollment, which is arranged by the management departments of clinical colleges. The rotation requirement not only meets the requirements of the state for clinical master, but also closely combines with the regular training. The second stage is the directional training of clinical competence in the Department for one and a half years, requiring students to serve as 24-hour resident for not less than 6 months, with a total time of not less than 33 months, which conforms to the regulations [12]. Requirements for the first stage of training. For non-graduate students, we adopt the "fill-in" training method, that is, accurately record the clinical rotation time of clinical master, and add up the previous training time to meet the requirements of training time. Students who have obtained the certificate of resident standardization training are directly transferred to specialist training (i.e. the second stage of standardization training), which not only saves the time for graduate students to carry out clinical rotation, but also ensures the quality of training, and achieves seamless docking in the rotation cycle.

\subsubsection{Establishment of Quantitative Assessment Index System for Clinical Ability}

Clinical competence is the core of clinical master training. How to objectively and effectively assess the clinical competence of postgraduates is the key to ensure the quality of clinical medicine degree award. At present, the country lacks a quantitative index system for clinical competence evaluation system. Therefore, according to their own characteristics, each unit has formulated a variety of assessment indicators system, and its level is uneven, resulting in different clinical ability of clinical master. The main reason for this phenomenon is that since the trial implementation of clinical medical professional degree, the state has not evaluated the quality of the pilot units and lacked an effective monitoring mechanism.

School research and explore more rigorous clinical training and assessment methods. There are mainly "pre-job training", "centralized departure assessment", "stage assessment" and "annual assessment"[13]. The school has established a multi-level and whole-process clinical competence assessment system, which is suitable for clinical master's clinical competence assessment and regular training and graduation assessment.

\subsection{Reform of Award Criteria}

The Interim Measures for the Implementation of the Regulations on Academic Degrees of the People's Republic of China promulgated in 1981 stipulates that before the postgraduate's reply, the degree-granting unit shall employ one or two experts from the disciplines concerned with the thesis to review the thesis. The clinical master emphasizes on examining the clinical competence of postgraduates. If the reviewers are hired, some experts will evaluate the papers according to the requirements of scientific degree papers. In order to pass the papers evaluation smoothly, postgraduates will increase the difficulty of scientific research, which directly affects the students' clinical rotation. Before graduation, clinical masters not only have to defend their dissertations, but also have to pass strict clinical competence assessment, which increases the workload of students. At the same time, the cost of training clinical masters has increased substantially. Compared with academic degree postgraduates, the training objectives of professional degree postgraduates are obviously different. The school revises the standard of clinical master's degree award, which reduces the requirement of publishing articles. It stipulates that clinical master can apply for a degree only by publishing a review or case analysis. Postgraduates can devote all their energy and time to clinical ability training.

\subsection{Improving the Understanding of Professional Degree Education of Tutors and Managers}

Schools from several aspects to improve the mentors, managers and related personnel of clinical master's education 
awareness: First, extensive publicity. The school regularly carries out the training of tutors and managers, explaining in detail the strategic development direction of national postgraduate education and the related policies of clinical master's education in our school. Second, in-depth research. The staff of the Graduate Management Department of the school conducted a thorough investigation on the effect, problems and suggestions of the reform of the training mode of clinical master in various clinical colleges and departments, and organized a meeting to solve some common problems. Thirdly, we should formulate an enrollment system conducive to the development of professional degrees. The number of professional degree postgraduates enrolled by tutors in clinical departments is clearly required. All tutors working in clinical departments must enroll professional degree postgraduates. Fourth, direct link the workload of tutors' guidance to professional degree postgraduates with the promotion of their professional titles, so as to improve the enthusiasm of tutors' guidance to professional degree postgraduates.

\section{The Main Characteristics of the Reform of the Training Model for Postgraduates with Master's Degree in Clinical Medicine in Chongqing Medical University}

\subsection{Creatively Solved the Contradiction Between Health Policy and the Training Goal of Postgraduates with Master's Degree in Clinical Medicine}

There are three difficult problems in the training process of master's degree postgraduates of clinical medicine specialty: first, the graduates of clinical medicine specialty with bachelor's degree must work in medical institutions for one year before they can apply for the qualification of practicing physician; second, the graduates with bachelor's degree can't obtain the qualification certificate of practicing physician and can't carry out clinical training; third, some of the graduates with bachelor's degree must work in medical institutions for one year. Qualification certificate students are not allowed to practise medicine in other places in accordance with the Law of Licensed Physicians, so it is difficult to carry out clinical training [14]. The school has won the strong support of the higher authorities, and all the above problems have been effectively solved.

\subsection{We Took the Lead in Creating a "5+3" Innovative Training Model for Postgraduates with Clinical Master's Degree, Which Can Be Popularized and Implemented in an All-round Way}

By promoting the combination of clinical master training and regular training, the problem of clinical master qualification certification has been solved, and a new " $5+3$ " training mode has been constructed. This model is based on practice in an all-round way, does not need the national single enrollment index, does not need the national special allocation, has the characteristics of innovation, practicability, commonality, feasibility, and has the realistic basis for comprehensive promotion and implementation.

\subsection{A New Training Model for Clinicians with Great Popularization Value has Been Constructed}

The school has thoroughly reformed the training mode of clinical master, organically docked school education with post-graduation education and lifelong education, promoted the seamless docking of professional degree education with industry access standards, accelerated the internationalization process of higher medical personnel training mode, and formed a new systematic training mode for clinical doctors, which has great application value in the whole country.

\subsection{Formed a Mature Seamless Docking Scheme Between Professional Degree Education and Industry Access Standards}

In view of the characteristics of professional degree postgraduate education, the school grasps the development trend of postgraduate education, and closely combines the admission criteria with the industry admission criteria in all aspects of enrollment, cultivation and award of posts, which ensures the complete docking of personnel training and qualifications, and provides mature experience for the seamless docking of professional degree education and Industry admission criteria in China. It provides a mature reference model for the docking of professional degree postgraduate education and industry access standards in other fields in China.

\subsection{A systematic Quality Assurance System for Training has Been Formed and Remarkable Economic and Social Benefits have Been Achieved}

The new "5+3" training mode built by the school covers all aspects of training, such as curriculum system, assessment system, award system, award system, rotation system, tutor system and management mode. It fully guarantees the quality of clinical master training and brings up a large number of high-level applied medical talents for Chongqing and even the whole central and Western regions, which has produced remarkable economic and social effects. Benefit.

\subsection{Innovation of Training Mechanism to Realize the Integration of Postgraduate Training of Clinical Master's Degree and Standardized Resident Training}

The school has continuously innovated the training mechanism and formed a "modular" curriculum system and a quantitative assessment system for clinical competence. The curriculum system is guided by the improvement of vocational competence and solves the contradiction between curriculum learning and clinical competence training. The clinical competence assessment system checks the training process from qualitative and quantitative aspects, and achieves the 
whole process management [15]. The two systems complement each other and organically combine to realize the training of clinical master and regular training.

\subsection{Reform the Management System and Mechanisms to Actively Adapt to Professional Degree Education}

The school has set up a clinical medical degree supervision group, which is specially responsible for the supervision of the training process of clinical master's degree. The school has reformed the single tutor system and explored the establishment of clinical master tutor group system. In view of the characteristics of clinical master's degree, the school has established a funding system different from academic degree postgraduates. Secondary colleges have set up a special post-graduate management office to coordinate the implementation of the reform of the training mode of their departments.

\section{The Main Results of the Reform of the Training Mode for Postgraduates with Master's Degree in Clinical Medicine in Chongqing Medical University}

Since 2009, the school began to explore the reform of the training mode of clinical master in an all-round way. It has overcome many obstacles and steadfastly promoted the reform. It has basically realized the seamless connection between the degree education of clinical medicine specialty and the certification of professional qualification. Over the past five years, the reform has achieved fruitful results and basically achieved the expected goals. The main results are as follows:

\subsection{Promoting the Reform of "5+3" Training Mode for Postgraduates with Master's Degree in Clinical Medicine}

The reform breaks through the restrictions of relevant industry policies on the training objectives and modes of clinical master, and provides innovative modes for brothers to learn from. Dozens of brothers such as Fudan University learn from our experience. This model is in line with the reality of the development of medical and health care and higher education in China. It has been highly valued by the Ministry of Education and the Health Planning Commission, and has the realistic conditions for its promotion and implementation throughout the country.

\subsection{Improving the Overall Training Quality of Clinical Master's Degree Postgraduates}

In the past five years, a total of 2063 clinical masters enrolled in the school have been integrated into the training. Many excellent students have become an indispensable new force in clinical colleges. They have achieved the ultimate goal of training "doctors who can really see a doctor". The employment rate of graduates has been guaranteed to be $100 \%$ for a long time. They have trained a large number of high-level applied medical talents for Chongqing and the whole central and Western regions, promoted the development of health undertakings in the central and Western regions, and produced remarkable economic and social benefits [16].

\subsection{It Has Played an Exemplary, Leading and Leading Role in the Field of Postgraduate Education for Master's Degree in Clinical Medicine}

In the 2011 "Forum on Reform and Development of Medical Education", the principal of the school presented the reform experience to the conference and won the unanimous praise of the broad masses of colleagues. In December 2013, the school sponsored the National Symposium on the Reform of the Training Model of Clinical Master's Degree Postgraduates. The leaders of the Ministry of Education, the Health Planning Commission and more than 400 persons in charge of training units participated in the symposium, which greatly promoted the reform and development of clinical Master's training in China, and played a tremendous leading role in promoting the reform of the training model of clinical Master in the western region and even in the whole country.

\subsection{Reform Experience has Been Widely Recognized}

At present, the school has completed more than 10 research reports and published more than 30 academic papers on the sub-project "Construction and Practice of Quality Assurance System for Medical Degree Postgraduates" of the Ministry of Education Innovation Project. The article "Construction and Practice of Quality Assurance System for Master of Clinical Medicine Degree Postgraduates" published in "Degree and Graduate Education" won the second prize for Excellent Thesis of "Degree and Graduate Education", and it is also the only prize-winning thesis in the field of medical science. The article "Reforming the System and Mechanisms to Improve the Quality of Postgraduate Training for Master's Degree in Clinical Medicine" won the third prize for excellent dissertation at the "National Symposium on Degree Work in Clinical Medicine and Nursing in 2011" organized by the National Medical Degree Education Steering Committee, which is the only prize-winning dissertation in a single-discipline university. The article "Difficulties and Countermeasures of Establishing the Evaluation Index System of Clinical Ability of Master's Degree in Clinical Medicine" won the third prize of excellent thesis at the 10th National Annual Conference of Medical Degree and Graduate Education in 2014 organized by the Medical Working Committee of the Chinese Academy of Degree and Graduate Education.

\subsection{Enhanced the Ability of Personnel Training in Affiliated Hospitals}

Our school has 10 affiliated hospitals of Grade A and 28 key national clinical specialties. Since the implementation of the reform of the training mode of clinical master, the combination of degree education and vocational education in 
our school has become closer. There are 9694 open beds in each affiliated teaching hospital, 57 resident standardized training bases, covering all the specialty categories of clinical medicine. At present, five affiliated hospitals of our university have been appraised as model planning training bases of the State Health Planning Commission $(8$ hospitals in Chongqing).

\subsection{Enlarged Social Influence}

Since the reform of training mode, the enrollment of clinical masters in our university has been increasing rapidly. In the past five years, a total of 2063 clinical masters have been enrolled in the standardized resident training system. Professor Jin Xianqing and Professor Xie Peng were appointed members of the National Medical Graduate Education Steering Committee in 1998 and 2010 respectively. Professor Xie Peng, Professor Huang Ailong and Professor Wang Zhibiao were appointed experts of the Discipline Review Group of the Academic Degree Committee of the State Council. The school assists in formulating the standardized training policy for general practitioners and residents in Chongqing, the construction of bases, the training and assessment system, and teacher training.

\section{Conclusion}

The " $5+3$ " reform of clinical medicine master's degree in Chongqing Medical University has established a "one goal", that is, to train "doctors who really can see a doctor", and established the basic principles of the reform of training mode of clinical medicine master's degree and the training of clinicians. The establishment of "two sets of systems", namely curriculum system and assessment system, has solved the problem of insufficient clinical practice ability of master of clinical medicine and improved the overall quality of training. The implementation of "three combinations", namely, the combination of enrollment and enrollment, training and training, degree award and physician access. It has solved the difficult problem of registering for medical examination for master of clinical medicine in our university and effectively connected the training of master of clinical medicine with the regular training of master of clinical medicine. The "four certificates association" should be implemented, namely "licensed physician qualification certificate", "standard training qualification certificate", "diploma certificate" and "degree certificate" [17]. The problem of docking professional degree education with industry access standards has been solved. We should build "five guarantees", innovate the management system and mechanism, and ensure that the reform is in place. It has effectively solved the problems of imperfect training mode of clinical master, lack of mature training mode of high-level clinicians, low overall training quality of clinical master, inability to apply for the qualification of licensed physician, difficulty in effectively linking up with regular training, and difficulty in seamlessly linking professional degree education with industry access standards. The current management system and mechanism are not suited to the key issues of clinical medicine master training, such as the development of professional degree postgraduate education [18].

\section{Epilogue}

Chongqing Medical University combines many years of clinical master's education practice, highlights its own characteristics, gives full play to the advantages of running a school, and strives to solve the problem of linking professional degree education with vocational qualification certification. Through a series of reforms, it has achieved relatively ideal results and accumulated rich experience in reform. It hopes that through continuous exploration and reform, it can play a role in attracting more brothers. The unit pays attention to the degree education of clinical medicine specialty, strengthens the exchange study, improves the quality of medical higher education in our country, realizes the seamless connection between degree education of clinical medicine specialty and professional qualification certification, and explores the new mode of integrating medical education of our country with international practice.

\section{Acknowledgements}

This paper is part of the research results of the key topics of the Chongqing Graduate Education and Teaching Reform Research Project, "The Report on the Development of Graduate Education Quality in Chongqing" (No. yjg152029) and "The Research on the Development of Graduate Education Quality in Chongqing in 2016" (No. yjg20162033).

\section{References}

[1] Wu Zhenru, Lu Shuyun, Wang Taifu. History of Graduate Education and Degree System of the People's Republic of China. Beijing: Beijing University of Technology Press, 2001: 187.

[2] Chen Dilong, Xie Peng, Wang Ling, et al. Construction and practice of quality assurance system for postgraduate training of clinical medicine. Degree and postgraduate education, 2011 (7): 73-75.

[3] Hu Weili, Chen Dilong, Chen Yiting, et al. Difficulties and Countermeasures of "two-track integration" between postgraduate education of clinical medicine degree and standardized resident training. Degree and postgraduate education, 2013 (2): 41-45.

[4] Huang Baoyin. A New Era of the Development of Professional Degree Graduate Education in China. Degree and Graduate Education, 2010 (10): 2-6.

[5] Chen Rui. Historical Review of the Postgraduate Enrollment Examination System in China. China Examination, 2006 (04): 3-5.

[6] Pan Jinlong. Reflections on the admission system of graduate students in Colleges and universities. Journal of Armed Police College, 2006 (8): 9-11. 
[7] Yu Yingyu. Research on the Reform of China's Postgraduate Enrollment Examination System. Heilongjiang Higher Education Research, 2010 (10): 21-23.

[8] $\mathrm{Hu}$ Weili, Chen Yiting, Chen Dilong. Difficulties and Countermeasures of clinical competence assessment for master's degree postgraduates in clinical medicine. Chongqing Medical Science, 2015, 44 (9): 3733-3735.

[9] Hu Weili, Chen Yiting, Chen Dilong et al. Difficulties and Countermeasures of strengthening clinical competence training of postgraduates with master's degree in clinical medicine based on "5+3" reform. Degree and postgraduate education, 2016 (8): 29-33.

[10] Chen Qi, Shen Chunming, Chen Dilong et al. Construction and practice of five quality assurance systems for postgraduate education of clinical medicine degree. Chongqing Medical Science. 2013, (13): 1555-1556.

[11] $\mathrm{Wu}$ Susu, Wang Yunlan. On the development and standardization of the re-examination for master's degree students. Heilongjiang Education (Higher Education Research and Evaluation), 2006 (10): 16-19.

[12] Zuo Xiuxian. Recruitment of postgraduates should be standardized. Chinese postgraduates, 2004 (4): 18-19.
[13] Jia Xiaojun and Zhou Huadong. Exploration of new ideas for training excellent doctoral students in clinical medicine. Chongqing Medical Science, 2008 (4): 738-739.

[14] Ren Guosheng et al. Specialist training project is a platform for the growth of medical talents in the 21 st century. Medical education exploration, 2009 (2): 128-129.

[15] Shan Jing, Fan Yake, Sun Rong. Thoughts and Practice on Improving the Internal Quality of Specialist Training Base. Northwest Medical Education, 2009 (10): 863-864.

[16] Hu Weili, Chen Yiting, Duan Changzhu, et al. Deepening the reform practice and deep dilemma of postgraduate enrollment system for clinical medicine degree in the perspective of medical-educational cooperation. Degree and postgraduate education, 2018 (7): 34-38.

[17] Hu Weili, Chen Yiting, Xie Peng. Difficulties and Countermeasures of strengthening clinical competence training of postgraduates with master's degree in clinical medicine based on "5+3" reform. Degree and postgraduate education, 2016 (8): 29-33.

[18] Hu Weili, Duan Changzhu, Chen Dilong. Research on the Joint Training of Postgraduate Education and Specialist Standardization for Doctoral Degree of Clinical Medicine. Degree and Graduate Education, 2017 (11): 49-51. 